OPEN ACCESS

Edited by:

Ulrike C. Müller,

Heidelberg University, Germany

Reviewed by:

Stefan Lichtenthaler,

German Center for

Neurodegenerative Diseases (DZNE),

Germany

Claus Pietrzik,

Johannes Gutenberg-Universität

Mainz, Germany

*Correspondence:

Riqiang Yan

yanr@ccf.org.

Received: 19 October 2016 Accepted: 22 March 2017

Published: 19 April 2017

Citation:

Yan R (2017) Physiological Functions of the $\beta$-Site Amyloid Precursor

Protein Cleaving Enzyme 1 and 2.

Front. Mol. Neurosci. 10:97. doi: 10.3389/fnmol.2017.00097

\section{Physiological Functions of the $\beta$-Site Amyloid Precursor Protein Cleaving Enzyme 1 and 2}

\author{
Riqiang Yan* \\ Department of Neurosciences, Lerner Research Institute, Cleveland Clinic Foundation, Cleveland, OH, USA
}

BACE1 was discovered as the $\beta$-secretase for initiating the cleavage of amyloid precursor protein (APP) at the $\beta$-secretase site, while its close homology BACE2 cleaves APP within the $\beta$-amyloid $(A \beta)$ domain region and shows distinct cleavage preferences in vivo. Inhibition of BACE1 proteolytic activity has been confirmed to decrease $A \beta$ generation and amyloid deposition, and thus specific inhibition of BACE1 by small molecules is a current focus for Alzheimer's disease therapy. While BACE1 inhibitors are being tested in advanced clinical trials, knowledge regarding the properties and physiological functions of BACE is highly important and this review summarizes advancements in BACE1 research over the past several years. We and others have shown that BACE1 is not only a critical enzyme for testing the "Amyloid Hypothesis" associated with Alzheimer's pathogenesis, but also important for various functions such as axon growth and pathfinding, astrogenesis, neurogenesis, hyperexcitation, and synaptic plasticity. BACE2 appears to play different roles such as glucose homeostasis and pigmentation. This knowledge regarding BACE1 functions is critical for monitoring the safe use of BACE1 inhibitors in humans.

Keywords: Alzheimer's disease, amyloid plaques, amyloid precursor protein, secretase, BACE1, BACE2, aspartic protease, BACE substrates

\section{INTRODUCTION}

For over 30 years, the study of $\beta$-amyloid $(\mathrm{A} \beta)$ peptides has been the largest field of research geared toward understanding Alzheimer's pathogenesis and therapeutic intervention. After the molecular cloning of amyloid precursor protein (APP; Kang et al., 1987; Tanzi et al., 1987), it became clear that $A \beta$ is a small fragment of APP that is located in the region partially spanning the transmembrane (TM) domain. The excision of A $\beta$ from APP requires the sequential cleavage of APP by both $\beta$ - and $\gamma$-secretase. In 1999, four groups independently reported identification of membrane-anchored aspartic protease as the $\beta$-secretase (Hussain et al., 1999; Sinha et al., 1999; Vassar et al., 1999; Yan et al., 1999), while the $\gamma$-secretase consists of presenilin-1 or -2, which forms a complex with additional multi-TM proteins nicastrin, pen2, and Aph1 (De Strooper et al., 1998; Wolfe et al., 1999; Li et al., 2000; Yu et al., 2000; Francis et al., 2002). After initial discovery, the $\beta$-secretase was named as BACE1, meaning $\beta$-site APP converting enzyme (Vassar et al., 1999). For the past 17 years, extensive efforts have been focused on the development of compounds that specifically inhibit BACE1 activity for Alzheimer's disease (AD) therapy, and several major hurdles of producing brain-penetrable small molecular inhibitors have been overcome. Several highly potent BACE1 inhibitors have been developed by pharmaceutical and biotech companies 
and have been advanced to phase II/III clinical trials (see reviews by Ghosh and Osswald, 2014; Oehlrich et al., 2014; Vassar, 2014; Yan, 2016). Concurrently, BACE1 has also been shown to cleave multiple membrane substrates and its physiological roles in neuronal functions continue to be revealed (Vassar et al., 2014; Yan and Vassar, 2014; Hu et al., 2015a; Barao et al., 2016). Because of the importance of BACE1 inhibitors for therapeutic benefits in $\mathrm{AD}$, this review will focus on summarizing the growing body of knowledge regarding the biological functions of BACE1.

\section{BACE1 IS A TYPICAL ASPARTIC PROTEASE}

In the initial molecular cloning of $\beta$-secretase, the Pharmacia group was exploring whether an aspartic protease functions as such a secretase (Yan et al., 1999). Two other groups had also screened for $\beta$-secretase activity through their aspartic protease collections (Hussain et al., 1999; Lin et al., 2000). Independently, all five groups demonstrated that the $\beta$-secretase is a type I TM aspartic protease having a classical bilobal structure with two active aspartate motifs $\left(\mathrm{D}_{93} \mathrm{TG}\right.$ and $\left.\mathrm{D}_{289} \mathrm{SG}\right)$. Although not broadly cited, this enzyme was also named to be memapsin 2 based on the standard nomenclature for aspartic proteases (Lin et al., 2000). The crystal structure of BACE1 shows gross similarity to other aspartic proteases, but the catalytic pocket is more open and less hydrophobic than that of other human aspartic proteases (Hong et al., 2000).

BACE1 is synthesized in the endoplasmic reticulum (ER) as a precursor protein having pre- (residues 1-21), pro(residues 22-45), core protease- (residues 46-460), TM- (residues 461-477), and C-terminal domains (residues 478-501). BACE2 has 518 amino acids and almost identical structural organization (Figure 1). Both proteins share 59\% identity and are two known aspartic proteases docked on the membrane through the type I TM domain (Hussain et al., 1999; Yan et al., 1999; Bennett et al., 2000; Lin et al., 2000). In the aspartic protease family, the prodomain usually assists in protein folding (Baker et al., 1993) and can flip to block the active pocket by conferring zymogen-like properties (Khan and James, 1998). Therefore, this prodomain is normally removed by furin-like proprotein convertases during maturation in the Golgi compartment to produce active enzyme. Interestingly, this prodomain has weak inhibitory effects and proBACE1 is enzymatically active (Shi et al., 2001). Consistent with this, BACE1 is active in the ER compartment (Yan et al., 2001a). While inhibiting prodomain removal has a weak effect on blocking BACE1 activity, enhancing shedding of BACE1 near the ectodomain region impacts its cleavage of APP. It is known that docking on the lipid bilayer is essential for BACE1 to cleave APP at the $\beta$-secretase site, as removing this TM domain abolishes cleavage of APP at the $\beta$-secretase site in cells (Yan et al., 2001a). This is consistent with observations that many soluble aspartic proteases cleave APP peptides at the $\beta$-secretase site in vitro, but not in vivo (Brown et al., 1996; Chevallier et al., 1997; Mackay et al., 1997; Gruninger-Leitch et al., 2000; Turner et al., 2002; Tomasselli et al., 2003).
BACE1 also undergoes other multiple post-translational modifications: it is $\mathrm{N}$-glycosylated on four sites (N-153, N-172, N-223, and N254; Haniu et al., 2000), acetylated on seven Lys residues (Lys-126, Lys-275, Lys-279, Lys-285, Lys-299, Lys-300, and Lys-307) in the ER (Costantini et al., 2007), ubiquitinated at Lys-501 for the control of endocytosis to lysosomes for degradation (Tesco et al., 2007; Kang et al., 2012) and at Lys-203 and Lys-382 for the proteasomal degradation of BACE1 (Wang R. et al., 2012), palmitoylated in four C-terminal Cys residues (Cys474/478/482/485) for lipid raft localization (Benjannet et al., 2001; Vetrivel et al., 2009; Bhattacharyya et al., 2013), and phosphorylated at Ser-498 (Walter et al., 2001), which is linked to BACE1 cellular trafficking (Pastorino et al., 2002; He et al., 2005). Phosphorylation of BACE1 at Thr252 by the p25/Cdk5 complex appears to increase BACE1 activity (Song et al., 2015). A recent study suggests that glycol modifications of BACE1 by $\mathrm{N}$-acetylglucosamine (GlcNAc), a sugar-bisecting enzyme highly expressed in brain, regulates BACE1 stability (Kizuka et al., 2015). Loss of GlcNAc will lead to enhanced degradation of BACE1 by increased trafficking of BACE1 to lysosomes from the late endosomes. This is reminiscent of deubiquitinylation by ubiquitin-specific peptidase 8 (USP8), an endosome-associated deubiquitinating enzyme. Studies have shown that RNAimediated depletion of USP8 increased BACE1 ubiquitination on Lys-501, promoted BACE1 accumulation in the early endosomes and late endosomes/lysosomes, and decreased levels of BACE1 in the recycling endosomes (Yeates and Tesco, 2016). It should be noted that most post-translational modifications, except for the disulfide linkage, can regulate BACE1 activity but are not necessary for BACE1 proteolytic activity per se, as recombinant BACE1 produced in bacteria lacks these modifications but is sufficiently active.

\section{CELLULAR TRAFFICKING OF BACE1}

BACE1 is first synthesized in the ER and then is distributed to various cellular compartments such as the Golgi network, endosomes, and cell surface, where the luminal BACE1 catalytic domain will cleave its cellular substrates such as APP. Like other aspartic proteases, the catalytic activity of BACE1 is elevated in more acidic environments (Shimizu et al., 2008). Because of this preferential activation, altered localization or cellular trafficking of BACE1 in cellular compartments impacts generation of $A \beta$ from the cleavage of APP (Vassar et al., 2009).

Several proteins have now been shown to bind BACE1 and to alter cellular localization. Golgi-localized $\gamma$-ears containing proteins from the ADP ribosylation factor-binding (GGA) family were first shown to bind to BACE1 via the dileucine motif, and this binding impacts not only BACE1 endosomal trafficking but also cellular stability (He et al., 2002, 2005; Wahle et al., 2005; Tesco et al., 2007; Santosa et al., 2011; Walker et al., 2012; von et al., 2015). Depletion of both GGA1 and GGA3 induces a rapid and robust elevation of BACE1, and such an effect is likely inhibited by flotillin, which can compete with GGA proteins for binding to the same dileucine motif in the BACE1 tail (John et al., 2014). Reticulon (RTN) proteins, mainly 


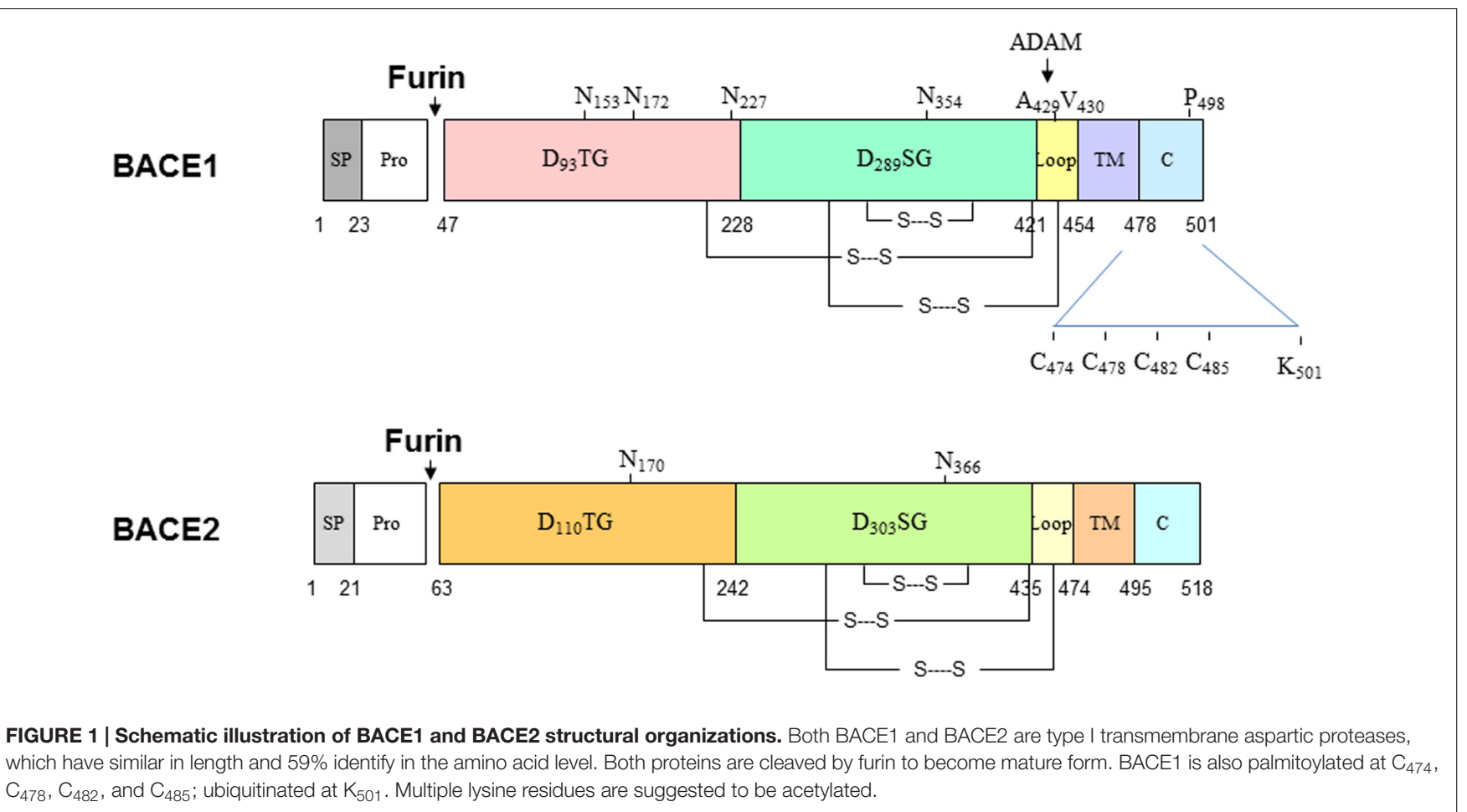

localized in the ER, have been shown to bind BACE1 and this binding induces retention of BACE1 in the ER, which has a relatively neutral $\mathrm{pH}$ environment and thus is less favorable for APP cleavage by BACE1 (Sharoar and Yan, 2017). On the other hand, increased trafficking of BACE1 to the more acidic endosomes by cellular trafficking proteins such as the Vps10p domain-sorting receptor sortilin (Finan et al., 2011), the small GTPase ADP ribosylation factor 6 (ARF6; Sannerud et al., 2011), Rab-GTPases Rab11 (Udayar et al., 2013), and Sorting nexin 12 (Zhao et al., 2012) results in significant increases in $A \beta$ generation.

In neurons, BACE1 is also targeted to axons and presynaptic terminals (Kandalepas et al., 2013) and its axonal transport is regulated by altered levels of calsyntenin-1 (Steuble et al., 2012; Vagnoni et al., 2012), retromer vps35 (Wen et al., 2011; Wang C.L. et al., 2012), RTN3 (Deng et al., 2013), Rab11 and Eps15 homology domain proteins (Buggia-Prevot et al., 2013, 2014; Udayar et al., 2013). The enhanced localization of BACE1 at synaptic sites is suggested to increase release of $A \beta$ by the synaptic terminals and directly facilitates amyloid deposition in AD patients (Sadleir et al., 2016).

\section{IDENTIFIED BACE1 SUBSTRATES}

BACE1 cleaves many cellular substrates other than APP, so its biological functions will be affected by altered cleavage of these substrates. Various biochemical and proteomic approaches have been employed to search for BACE1 substrates. Initially, optimal BACE1 cleavage sites were explored (Gruninger-Leitch et al., 2002; Turner et al., 2002; Tomasselli et al., 2003), but this effort together with the use of bioinformatic tools was not successful in determining potential substrates. Instead, several BACE1 substrates were identified through candidatebased characterizations. For example, neuregulin-1 (Nrg1) was identified via the finding that BACE1 plays a role in regulating myelination (Hu et al., 2006; Willem et al., 2006).

Using unbiased proteomic analysis of cultured media from cell lines with or without overexpression of BACE1, Selkoe and his colleagues reported 68 putative BACE1 substrates (Hemming et al., 2009). By using the developed secretome protein enrichment with click sugars (SPECS) method, Lichtenthaler and his colleagues identified 34 membrane-associated proteins as potential BACE1 substrates (Kuhn et al., 2012). This group has also compared cerebrospinal fluids from BACE1-null vs. wild-type mice using label-free quantitative proteomics, and they identified additional novel substrates while validating several previously reported substrates (Dislich et al., 2015). Among these reported BACE1 substrates, the proteins listed in Table 1 have gained the most attention and/or are fully validated.

\section{BIOLOGICAL FUNCTIONS ATTRIBUTABLE TO BACE1-CLEAVABLE SUBSTRATES}

As outlined above, the list of BACE1 substrates has grown in recent years (Table 1). It is highly important to understand the biological functions associated with BACE1 cleavage of these individual substrates. The following sections summarize studies on this topic that have been published in recent years. 
TABLE 1 | Partial list of characterized BACE1 substrates.

\begin{tabular}{|c|c|c|}
\hline Protein substrate & The substrate recognition site & Reference \\
\hline APP & KM $\downarrow D A E F R H D S G Y \downarrow E V H H Q K^{\vee} L V F F A E D V G S N K-T M$ & \\
\hline CHL-I & WGDNDSIFQ $\downarrow D V I E T R G R E T A G L D D I S T G-T M$ & Zhou et al., 2012 \\
\hline Delta-1 & GYVCECARGYGGPNCQFLLPELPPGPAWDL $\downarrow T E K L E G Q G G$ & Hu et al., 2017 \\
\hline IL-1R2 & PVTREDLHMDFKCWHNTLSF $\downarrow Q T L R T T V K E-T M$ & Kuhn et al., 2007 \\
\hline Jag1 & KE $\downarrow I T D K I I D L V S K R D G N S S L I A \downarrow A V A E^{\vee} \vee R V Q R R P L K N R-T M$ & He et al., 2014 \\
\hline Jag2 & LIQGAAHAIVAAITQRGNSSLLL $\downarrow$ AVTE ${ }^{\vee}$ VKVETWTGGS-TM & He et al., 2014 \\
\hline $\operatorname{Nav} \beta 2$ & IMNPPDRHRGHGKIHL $\downarrow Q V L \downarrow M E E P P E R D S T-T M$ & Gersbacher et al., 2010 \\
\hline Nrg1 (type I and III- $\beta 1 \alpha$ ) & GDRCQNYVMASF${ }^{\vee} Y K H L G I E F \downarrow M E A E E L Y Q K R-T M$ & Hu et al., 2008 \\
\hline Nrg1 (type III- $\beta 1 \alpha)$ & 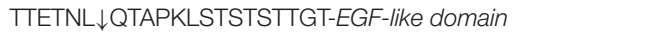 & Fleck et al., 2013 \\
\hline Nrg3 & FLPKTDSILSDPTDHLGIEF $\downarrow M E S E E V Y Q R Q-T M$ & Hu et al., 2013 \\
\hline PSGL-1 & VTHKGIPMAASNL $\downarrow S V N Y P V G A P D H I S V K Q C-T M$ & Lichtenthaler et al., 2003 \\
\hline Sez6 & AASLDGFYNGRSL $\downarrow D V A K A P A S S A L D A A H-T M$ & Pigoni et al., 2016 \\
\hline Sez6L & ICKVNQDSFEHALEA $\downarrow E A A A E S S L E G G N M A-T M$ & Pigoni et al., 2016 \\
\hline ST6Gal 1 & SGMAVKEQSKPMQFEKAQ $\downarrow L T L A E Y D S G K K-T M$ & Kitazume et al., 2003 \\
\hline
\end{tabular}

$\downarrow$ BACE2 cleavage site. ${ }^{\vee} \alpha$-secretase cleavage site.

\section{Astrogenesis and Neurogenesis}

BACE1 was found to cleave Jagged-1 (Jag1), a type I TM ligand for Notch receptors (Hu et al., 2013). BACE1 mainly cleaves Jag1 at the $\underline{A}_{1050}-\underline{A}_{1051}$ site near the TM domain (He et al., 2014), and abolished cleavage in BACE1-null mice causes elevation of full-length Jag1, which in turn enhances Notch activation by producing high levels of Notch intracellular domain (NICD; Hu et al., 2013). Notch is highly expressed during neonatal stages and then gradually declines, with persistent low levels of expression in adulthood. BACE1 and Jag1 expression concurrently have the exact same patterns: high levels in neonatal stages and gradual reduction thereafter. Such parallel expression patterns in early developmental stages imply indispensable roles during development. Indeed, BACE1 deficiency causes enhanced astrogenesis and reduced neurogenesis, which is restricted to the hippocampal dentate gyrus (Hu et al., 2013). BACE1 and Jag1 are mainly expressed by pyramidal neurons, while Notch is highly expressed in neural stem cells in the subgranular zone. In earlier studies, high NICD activity was shown to inhibit neurogenesis in the postnatal dentate gyrus and to act as a switch from neurogenesis to gliogenesis (Morrison et al., 2000; Breunig et al., 2007). Hence, it appears that BACE1 regulates Notch signaling, via cleavage of Jag1, to control proliferation and differentiation of multi-potent neural precursor cells into neurons or astrocytes in the early developmental hippocampus.

\section{Myelination and Remyelination}

The role of BACE1 in the control of myelination during development and of remyelination in the adult appears to occur through its cleavage of $\mathrm{Nrg} 1$ (Fleck et al., 2012; Hu et al., 2015a). Nrg1, which is one of the largest genes in the human genome with 33 spliced isoforms due to specific uses of six different transcriptional initiation sites as well as multiple splicing isoforms, is typically recognized by the presence of exons coding for the epidermal growth factor (EGF)-like domain (Holmes et al., 1992; Chang et al., 1997). Although $\mathrm{Nrg} 1$ isoforms with six different membrane topology types are found in the brain, types I and III $\beta 1 \mathrm{Nrg} 1$ isoforms are mainly expressed by neurons and have been established as BACE1 substrates (Hu et al., 2006, 2008; Willem et al., 2006; La et al., 2011; Fleck et al., 2013). BACE1 specifically cleaves $\mathrm{Nrg} 1$ at the F-M site, which is located 10 residues before the TM domain and is shared by both types I and III $\beta 1$ isoforms (Hu et al., 2008; La et al., 2011; Fleck et al., 2013). These two $\mathrm{Nrg} 1$ isoforms can also be cleaved by ADAM10 and ADAM17 at the F-Y site, which is seven residues upstream of BACE1 cleavage site. After cleavage by either BACE1 or ADAM10/17, type I Nrg1 releases its N-terminal fragment (Nrg1-ntf) to the extracellular space, where Nrg1-ntf binds to ErbB receptors (ErbB2 and ErbB3 heterodimers and ErbB4 homodimers) on nearby cells in a paracrine fashion, while type III Nrg1-ntf, which remains tethered to the lipid bilayer due to a hydrophobic CRD in its N-terminus, signals to adjacent cells in a juxtacrine fashion (Warren et al., 2006).

Activated Nrg1 signaling, mainly initiated by type III Nrg1, is critical for optimal myelination: mice with reduced Nrg1 signaling activity exhibit hypomyelination of peripheral nerves during development (Michailov et al., 2004; Taveggia et al., 2005). BACE1-null mice also display hypomyelination in their sciatic nerves, which are typically ensheathed by Schwann cells (Hu et al., 2006; Willem et al., 2006). This phenocopy is not only seen in BACE1-null mice but also in zebrafish (van Bebber et al., 2013) and rat (Weber et al., 2017) knockout (KO) models, and is consistent with reduced Nrg1 activity, which leads to decreased downstream signaling events such as reduced Akt phosphorylation and transcriptional expression of myelin genes like myelin basic proteins. Although type III Nrg1 is abundantly expressed in brain neurons (Liu et al., 2011), it has less effect on entheathing axons in the central nervous system, and both Nrg1 heterozygous mice and BACE1-null mice display weak hypomyelination phenotype in central nerves (Hu et al., 2006; Taveggia et al., 2008). Hypomyelination was observed in BACE1null optic nerves, but not in broad brain regions of BACE1-null mice (Hu et al., 2006). 
Interestingly, inhibition of BACE1 produces more dramatic suppression of myelination in a co-culture myelination system than pan inhibition of ADAM proteases (Luo et al., 2011). This is likely related to the presence of an additional BACE1 cleavage site between L-Q, located 16 residues upstream of the EGF-like domain in type III Nrg1 (Fleck et al., 2013). Cleavage of type III Nrg1 at these two BACE1 sites will release the EGF-like domain for signaling through ErbB receptors. This observation further supports the importance of BACE1-dependent Nrg1 signaling in myelination.

When peripheral nerves are severely injured, myelin on proximal segments of damaged axons can be removed due to Wallerian degeneration and regrowing axons will be remyelinated by Schwann cells via contacting regenerating axons in the proximal band of Büngner. BACE1 has been shown to be indispensable for remyelination in nerve crush experiments, as remyelinated axons remained hypomyelinated in BACE1null sciatic nerves ( $\mathrm{Hu}$ et al., 2008). In nerve transplantation experiments, it has been further demonstrated that nerve injury induces expression of BACE1 in Schwann cells and that this increased expression of BACE1 in Schwann cells is required for remyelination ( $\mathrm{Hu}$ et al., 2015b). nerve region leads to shortened internode as well as reduced nerve conduction. BACE1 is also required for initial and optimal remyelination of corpus callosum axons, as demonstrated in cuprizone-induced demyelination experiments (Treiber et al., 2012).

In peripheral nerves, BACE1 cleavages of type I Nrg1 in Schwann cells and type III Nrg1 in axons contribute to normal remyelination. This conclusion is supported by mouse genetic studies using conditional deletion of Nrg1 isoforms or transgenic mice overexpressing either type I or type III Nrg1 (Fricker et al., 2011, 2013; Stassart et al., 2013). These studies show that Schwann cell-derived type I Nrg1 is dispensable for developmental myelination and myelin maintenance, but is required for an autocrine signaling function for remyelination, as loss of Nrg1 expression in Schwann cells severely impairs remyelination after nerve crush. More recently, it is shown that BACE1 can cleave Jag1 and Delta1 in axons and Schwann cells, and abrogated cleavage of these two Notch ligands enhances Schwann cell proliferation ( $\mathrm{Hu}$ et al., 2017). This abnormally increased Schwann cell density within the given sciatic Hence, by cleaving types I and III Nrg1 as well as Jag1/Delta1 in different cell types, BACE1 controls these two signaling pathways to regulate optimal myelination and remyelination.

\section{Epileptic Seizures}

BACE1-null mice develop convulsive and spontaneous behavioral seizures in an age-dependent manner, beginning at a young age and becoming more frequent with aging (Kobayashi et al., 2008; Hitt et al., 2010; Hu et al., 2010). Longsustained epileptic seizures in BACE1-null mice likely contribute to neuronal loss in the 2-year-old mouse hippocampus, although neurodegeneration in this region was not evident in young mice (Hu et al., 2010). The molecular mechanism underlying this epileptic seizure activity remains elusive, and cleavages of multiple BACE1 substrates may each contribute. It has been shown that BACE1 cleaves voltage-gated sodium channel $\beta$ subunits (Kim et al., 2005; Wong et al., 2005; Huth et al., 2011). Voltage-gated sodium channels consist of a heterotrimeric complex of one $260 \mathrm{kDa} \alpha$-subunit and one or two auxiliary $\beta$ subunits (Catterall, 2000), and abolished cleavage in BACE1-null mice likely increases surface expression of ion-conducting, channel-forming $\alpha$-subunits through cellular trafficking (Isom, 2002; Yu et al., 2005). Sodium channel $\mathrm{Na}_{\mathrm{v}} 1.2$ protein was found to be elevated in BACE1-null hippocampal mossy fiber regions (Hu et al., 2010; Kim et al., 2011). This increase is consistent with greater neuronal excitability, as manifested by more frequent firing with larger amplitude in BACE1-null brain slices and a significant shift of the inactivation curve in the direction of depolarization (Dominguez et al., 2005; Hu et al., 2010). However, the BACE1- and subsequently $\gamma$-secretase-cleaved $\beta$ subunit is also known to enhance gene expression of $\mathrm{Na}_{\mathrm{v}} \alpha$ subunits (Kim et al., 2007) and BACE1 deficiency will reduce the level of $\mathrm{Na}_{\mathrm{v}} \alpha$ subunits (Kim et al., 2011). Pharmacological blockage of sodium channel activity was not sufficient to reduce seizure activities (Hitt et al., 2010). Hence, the altered activity of sodium channel activity is unlikely to be the only explanation for seizure activity.

BACE1 can also cleave KCNE1 and KCNE2, two auxiliary subunits of voltage-gated potassium channels (Sachse et al., 2013). Both KCNE1 and KCNE2 are expressed in brains and altered functions of these two proteins are linked to epileptic seizures (Goldman et al., 2009; Heron et al., 2010). On the other hand, BACE1 deficiency may cause epilepsy through a noneenzymatic mechanism, as BACE1 interacts with an M-currentproducing KCNQ (Kv7) family member, resembling the function of a $\beta$-subunit (Hessler et al., 2015). The loss of M-current due to BACE1 deficiency enhances neuronal excitability, which could also contribute to epileptic seizures.

Another family of proteins, the seizure-related gene 6 (Sez6) and its family member Sez6L, was identified as BACE1 substrate through an unbiased proteomic approach and was recently validated as a strong substrate of BACE1 (Kuhn et al., 2012). Their levels in BACE1-null CSF are significantly lowered, reflecting the abrogated cleavage by BACE1 (Pigoni et al., 2016). Although Sez6 KO mice have not been shown to have seizures, Sez6 is suggested to be a susceptibility gene for febrile seizures (Mulley et al., 2011). It remains to understand whether the abolished cleavage of Sez6 in BACE1-null mice contributes to epileptic seizures. Taking all of these findings into consideration, it is reasonable to postulate that multiple factors, including epigenetic factors, contribute to epileptic seizures in BACE1-null mice, which display variable spiking patterns on electroencephalography (Hitt et al., 2010; Hu et al., 2010).

\section{Muscle Spindle Defects}

Muscle spindles, which are composed of specialized intrafusal muscle fibers, are innervated by afferent axons extending from sensory neurons (Hunt, 1990). Nrg1 in sensory neurons transduces its signals through ErbB2/ErbB3 receptors in muscles to control the formation of muscle spindles (Andrechek et al., 2002; Hippenmeyer et al., 2002; Leu et al., 2003). BACE1 deficiency impairs coordinated muscle function between forelimbs and hindlimbs, resulting in a swaying walking pattern 
as well as a reduction in the number of muscle spindles (Cheret et al., 2013). Such an ambulatory defect, likely due to dysfunctional proprioception governed by muscle spindles, is more dramatic in newborns while less severe in BACE1-null adult mice or heterozygous mice (Cheret et al., 2013). This role of BACE1 in reduced muscle spindle maintenance is due to abrogated or reduced cleavage of Ig domain-containing type I $\beta 1 \mathrm{Nrg} 1$ (IgNrg1 $\beta 1$ ) isoforms, which are preferentially expressed by proprioceptive sensory neurons and are sufficient to induce muscle spindle differentiation in animals (Hippenmeyer et al., 2002). Consistently, transgenic mice overexpressing $\operatorname{IgNrg} 1 \beta 1$ develop supernumerary muscle spindles (Rumsey et al., 2008). If wild-type mice are treated with the BACE1 inhibitor Ly2811376 for 29 days, up to $40 \%$ of muscle spindles are lost (Cheret et al., 2013). As discussed previously (Hu et al., 2015a), abolished cleavage of Nrg1 reduces the expression of transcription factors in the early growth response (Egr) family. Egr3, in particular, controls expression of the muscle spindle-specific genes necessary for forming muscle spindle fibers. Hence, BACE1-dependent type I IgNrg1 $\beta 1$ signaling is critical for motor coordination.

\section{Axonal Growth and Neuronal Migration Defects}

The neural cell adhesion molecule close homolog of L1 (CHL1), which is a type I membrane protein and a component of Sema3A receptors, is a natural BACE1 substrate with identified cleavage sites located between $\mathrm{Y}_{1086}$ and $\mathrm{E}_{1087}, 18$ residues upstream of the TM domain (Kuhn et al., 2012; Zhou et al., 2012). After BACE1 cleavage, which is inducible by Sema3A, CHL1-ntf, and CHL1-ctf are released. The CHL1-ctf appears to induce growth cone collapse in thalamic neurons (Barao et al., 2015), while the soluble CHL1-ntf may interact with neuropilin-1 to influence axon guidance (Hitt et al., 2012; Kuhn et al., 2012; Zhou et al., 2012). BACE1-null mice show axon pathfinding defects with mistargeting olfactory sensory neuron projections to glomeruli in the olfactory bulb and a shortened and disorganized infrapyramidal bundle of the mossy fiber projection from the dentate gyrus to CA3 in the hippocampus (Rajapaksha et al., 2011; Cao et al., 2012; Hitt et al., 2012). It should also be noted that BACE1 and CHL1 are co-localized in the terminals of hippocampal mossy fibers, olfactory sensory neuron axons, and growth cones of primary hippocampal neurons, and that axonal defective phenotypes in BACE1-null mice and CHL1-null mice are correlated, confirming the importance of BACE1 cleavage of CHL1 in neuronal development.

\section{Synaptic Dysfunctions}

The effects of BACE1 inhibition on APP- or A $\beta$-mediated synaptic functions has recently been summarized in a separate review (Yan et al., 2016). As mentioned above, BACE1 can cleave type I Nrg1, which is highly important for synaptic functions through the signaling of ErbB4 receptors in the brain (see recent comprehensive review by Mei and Nave, 2014). More relevantly, Nrg1 has been identified as a susceptible gene in schizophrenia, which is a disease of synaptic dysfunction (Stefansson et al., 2002) and BACE1-null mice display schizophrenia-like behaviors, which include positive (hyperactivity and pre-pulse inhibition), negative (social withdrawal), and panel (cognitive functions) behaviors (Savonenko et al., 2008). In recent years, altered functioning of Nrg3, a member of the Nrg gene family, has also been found in association with schizophrenia pathogenesis. Nrg3 is an identified BACE1 substrate (Hu et al., 2008), further showing the importance of BACE1-dependent Nrg1 signaling functions. While hypo-function of Nrg1 is linked to schizophrenia-like behaviors in BACE1-null mice, enhanced expression of either BACE1-cleaved Nrg1-ntf fragment or of full-length Nrg1 surprisingly also induces schizophrenia-like behaviors (Kato et al., 2010; Luo et al., 2013; Yin et al., 2013; Agarwal et al., 2014). This is in line with clinical observations that increased Nrg1 or ErbB4 transcripts and proteins are found in schizophrenia patients (Harrison and Law, 2006; Geddes et al., 2011), supporting the importance of balanced BACE1-cleaved Nrg1 in synaptic functions.

BACE1-null mice also exhibit other synaptic dysfunctions. By electrophysiological recording of brain slices, it was demonstrated that hippocampal activity-dependent long-term potentiation at mossy fibers to CA3 is impaired, while long-term depression is increased (Wang et al., 2008, 2014). Intriguingly, a recent study reported that mice treated with the BACE1 inhibitors SCH1682496 and LY2811376 show impaired cognitive functions (Filser et al., 2015). As the list of identified BACE1 substrates has continued to grow (Hemming et al., 2009; Kuhn et al., 2012; Dislich et al., 2015), many of these potential substrates have been shown to control synaptic plasticity and their roles in BACE1-dependent synaptic functions have begun to gain attention. One such example discussed earlier is Sez6, which has been shown to play a role in synaptic function (Gunnersen et al., 2007). In Sez6 KO mice, dendritic spines are significantly shorted and excitatory synapses are thinner in the deep-layer pyramidal neurons of the somatosensory cortex, showing the importance of Sez6 in forming dendritic arbors and controlling synaptic plasticity. More roles of other BACE1 substrates are likely to emerge over the coming years.

\section{Retinopathy}

The role of BACE1 in retinal pathophysiology has gained increasing attention in recent years, as several BACE1 inhibitors have been found to cause retinal thinning, lipofuscin accumulation, and vascular dysfunction, which terminated clinical trials (Fielden et al., 2015). BACE1 was initially suggested to mediate these retinopathies in a report that BACE1-null mice were found to develop retinal thinning, apoptosis, reduced retinal vascular density, and an increase in age pigmentation and lipofuscin (Cai et al., 2012). The mechanism is linked to the BACE cleavage of vascular endothelial growth factor receptor (VEGFR1). However, the retinal phenotypes in BACE1-null mice are controversial and are not seen in all lines of BACE1-null mice or in BACE1-null rat (Fielden et al., 2015), suggesting possible off-target toxicity. While retinopathy is closely monitored in BACE1 inhibitor clinical trials, recent studies have shown that it is likely due to cross-inhibition of cathepsin D by BACE1 inhibitors (Zuhl et al., 2016). Likely, this side effect can be 
TABLE 2 | Characterized BACE2 substrates.

\begin{tabular}{|c|c|c|}
\hline Protein substrate & The substrate recognition site & Reference \\
\hline APP & KMDAEFRHDSGYEVHHQK`LVF $\downarrow F \downarrow A E D V G S N K-T M$ & Farzan et al., 2000; Yan et al., 2001b \\
\hline IAPP (human) & KCNTATCATQRLANF $\downarrow L V H S S N N F \downarrow G A I S S T N V G S N T Y-T M$ & Rulifson et al., 2016 \\
\hline IAPP (rodent) & KCNTATCATQRLANF $\downarrow L V R S S N N L G P V L P P T N V G S N T Y-T M$ & Rulifson et al., 2016 \\
\hline Jag1 & KEITDKIIDL $\downarrow V S K R D G N S S L I A \downarrow A V A E^{\vee} \vee R V Q R R P L K N R-T M$ & He et al., 2014 \\
\hline Tmem27 & RMNKNRINNAF $\downarrow F L \downarrow N D Q T L E F \downarrow L K I P S T L A P P-T M$ & Esterhazy et al., 2012 \\
\hline
\end{tabular}

$\downarrow$ BACE2 cleavage site. ${ }^{\vee} \alpha$-secretase cleavage site.

mitigated by developing BACE1 inhibitors with minimal offtarget inhibition of other aspartic proteases such as cathepsin D and $\mathrm{E}$, both of which are important in lysosomal functions.

On the other hand, specific inhibition of BACE1 is likely to benefit retinal functions, as BACE1 activity in retina is elevated in response to stress conditions such as mitochondrial respiratory inhibition or oxidative stress (Xiong et al., 2007). It has been suggested that changes in BACE1 expression appear earlier in the retina than in the brain and precede behavioral deficits, and abnormal expression of BACE1 in the retina appears to be an early pathological change in APP/PS-1 transgenic mice (Li et al., 2016). BACE in the adult retina is mostly present in the plexiform layers, consistent with localization of this enzyme to synaptic terminals (Xiong et al., 2007). In $\mathrm{AD}, \mathrm{A} \beta$ levels are elevated in neurodegenerative retinas, and this potentially causes damage in retinal function in aging (Dentchev et al., 2003; Gupta et al., 2016; Masuzzo et al., 2016). In this sense, inhibition of BACE1 will be beneficial to retinal function.

\section{BACE2 SUBSTRATES AND ITS BIOLOGICAL FUNCTIONS}

While BACE2 was discovered simultaneously with BACE1 (Vassar et al., 2014), the functional importance of BACE2 has emerged after the finding that BACE2 cleaves the proproliferative plasma membrane protein Tmem 27 and PMEL (see summary in Table 2). In pancreatic MIN6 cells treated with a BACE2 inhibitor or siRNA, BACE2 was initially shown to mediate insulin receptor $\beta$-subunit (IR $\beta$ ) expression and surface trafficking (Casas et al., 2010). A separate BACE2 silencing study in murine and human $\beta$ cells reveals Tmem27, known to promote the preservation of functional $\beta$-cell mass, as a BACE2 substrate (Esterhazy et al., 2011). Mice with BACE2 deficiency have been shown to correlatively increase $\beta$-cell mass, and improved control of glucose homeostasis is associated with increased insulin levels. Hence, BACE2 inhibition should be beneficial to diabetic patients by controlling $\beta$-cell maintenance and glucose metabolism.

To maintain glucose homeostasis, islet amyloid polypeptide (IAPP) in pancreatic $\beta$ cells needs to co-secrete with insulin, and the formation of IAPP amyloid is a hallmark pathological feature of type 2 diabetes (Mukherjee et al., 2015). BACE2 was recently shown to cleave IAPP at two ectodomain sites (Rulifson et al., 2016) and loss of BACE2 cleavage likely increases IAPP homodimer formation and subsequent production of cytotoxic oligomers and amyloid fibrils. Hence, this study suggests that BACE2 inhibition may lead to $\beta$-cell dysfunction due to IAPP accumulation in proteinaceous plaques in and around pancreatic islets. These two controversial aspects will be further resolved in more detailed future studies.

On the other hand, BACE2 inhibition can cause loss of pigmentation, as BACE2 cleaves the integral membrane form of PMEL within the juxtamembrane domain and exerts its role in melanosome biogenesis (Rochin et al., 2013). Although BACE1 is expressed in pigment cells, the level of BACE2 is 37-fold higher as that in retinal pigment epithelial cells, suggesting that BACE2 is the major BACE homolog in pigment cells. Consistently, mice with BACE2 deficiency show loss of pigment in skin and retina. However, BACE2 depletion reduces neither the number of stage IV melanized melanosomes nor the total melanin content. Instead, the loss of BACE2-cleaved PMEL N-terminal fragment impairs the organization of PMEL fibrils into parallel sheets, with a threefold decrease in the number of fibrillar stage II and III melanosomes and a sixfold increase in the number of round organelles containing unstructured aggregates. Hence, BACE2 is required for the formation of PMEL amyloid fibrils and for melanosome morphogenesis, consistent with demonstrations by pharmacological inhibition of BACE1 and BACE2 (Shimshek et al., 2016).

It is also demonstrated that Sez6L and Sez6L2 are effectively cleaved but in rate limiting proteolytic manner in pancreatic islet $\beta$-cells by BACE2 (Stutzer et al., 2013). Although Sez6L is also a BACE1 substrate, it is not cleaved by BACE1 in pancreatic cells (Pigoni et al., 2016). Additional BACE2 substrates, explored through proteomic approaches, include CD200, IGF2R, LAMP2, MPZL1, and SORT1 (Stutzer et al., 2013). The functional importance of BACE2 cleavages of these proteins remains to be established.

\section{SUMMARY}

Inhibition of BACE1 is one the most promising therapeutic targets for treating $\mathrm{AD}$, and five drugs have currently entered into clinical trials (Vassar, 2014; Yan, 2016). While there is great promise for BACE1 inhibition in benefiting Alzheimer's patients, it also raises caution regarding mechanism-based side effects associated with long-lasting inhibition of this enzyme. In addition to the fact that BACE1 is indispensable for proper astrogenesis, axonal growth and migration, myelination and remyelination, 
neuronal excitation, and synaptic plasticity, BACE1-null mice are also found to be susceptible to early lethality (Dominguez et al., 2005; Weber et al., 2017). Reduced body weight is seen in BACE1-null mice but not in rats. With more efforts, the available BACE1-null mice and rats will identify more shared phenotypes, and these phenotypes will have to be taken into consideration when BACE1 is inhibited for long terms. Moreover, BACE1 inhibition may also cause cross-inhibition with BACE2, as some compounds such as MK8931 appear to be more potent in blocking BACE2 activity (see reviews by Yan, 2016). Although BACE1 and BACE2 exhibit distinct cleavage specificity, substrates like APP, Jag1 and Sez6 family proteins are shared by these two enzymes. The number of studies using BACE2-null mice is increasing, and inhibition of BACE2 may alter glucose homeostasis and pigmentation. Future studies are expected to provide more knowledge regarding the

\section{REFERENCES}

Agarwal, A., Zhang, M., Trembak-Duff, I., Unterbarnscheidt, T., Radyushkin, K., Dibaj, P., et al. (2014). Dysregulated expression of neuregulin-1 by cortical pyramidal neurons disrupts synaptic plasticity. Cell Rep. 8, 1130-1145. doi: 10.1016/j.celrep.2014.07.026

Andrechek, E. R., Hardy, W. R., Girgis-Gabardo, A. A., Perry, R. L., Butler, R., Graham, F. L., et al. (2002). ErbB2 is required for muscle spindle and myoblast cell survival. Mol. Cell. Biol. 22, 4714-4722. doi: 10.1128/MCB.22.13.4714-4722. 2002

Baker, D., Shiau, A. K., and Agard, D. A. (1993). The role of pro regions in protein folding. Curr. Opin. Cell Biol. 5, 966-970. doi: 10.1016/0955-0674(93)90078-5

Barao, S., Gartner, A., Leyva-Diaz, E., Demyanenko, G., Munck, S., Vanhoutvin, T., et al. (2015). Antagonistic effects of BACE1 and APH1B-gamma-secretase control axonal guidance by regulating growth cone collapse. Cell Rep. 12, 1367-1376. doi: 10.1016/j.celrep.2015.07.059

Barao, S., Moechars, D., Lichtenthaler, S. F., and De Strooper, B. (2016). BACE1 physiological functions may limit its use as therapeutic target for Alzheimer's disease. Trends Neurosci. 39, 158-169. doi: 10.1016/j.tins.2016.01.003

Benjannet, S., Elagoz, A., Wickham, L., Mamarbachi, M., Munzer, J. S., Basak, A., et al. (2001). Post-translational processing of beta-secretase (betaamyloid-converting enzyme) and its ectodomain shedding. The pro- and transmembrane/cytosolic domains affect its cellular activity and amyloid-beta production. J. Biol. Chem. 276, 10879-10887. doi: 10.1074/jbc.M009899200

Bennett, B. D., Babu-Khan, S., Loeloff, R., Louis, J. C., Curran, E., Citron, M., et al. (2000). Expression analysis of BACE2 in brain and peripheral tissues. J. Biol. Chem. 275, 20647-20651. doi: 10.1074/jbc.M002688200

Bhattacharyya, R., Barren, C., and Kovacs, D. M. (2013). Palmitoylation of amyloid precursor protein regulates amyloidogenic processing in lipid rafts. J. Neurosci. 33, 11169-11183. doi: 10.1523/JNEUROSCI.4704-12.2013

Breunig, J. J., Silbereis, J., Vaccarino, F. M., Sestan, N., and Rakic, P. (2007). Notch regulates cell fate and dendrite morphology of newborn neurons in the postnatal dentate gyrus. Proc. Natl. Acad. Sci. U.S.A. 104, 20558-20563. doi: 10.1073/pnas.0710156104

Brown, A. M., Tummolo, D. M., Spruyt, M. A., Jacobsen, J. S., and SonnenbergReines, J. (1996). Evaluation of cathepsins D and G and EC 3.4.24.15 as candidate beta-secretase proteases using peptide and amyloid precursor protein substrates. J. Neurochem. 66, 2436-2445. doi: 10.1046/j.1471-4159.1996. 66062436.x

Buggia-Prevot, V., Fernandez, C. G., Riordan, S., Vetrivel, K. S., Roseman, J., Waters, J., et al. (2014). Axonal BACE1 dynamics and targeting in hippocampal neurons: a role for Rab11 GTPase. Mol. Neurodegener. 9:1. doi: 10.1186/17501326-9-1

Buggia-Prevot, V., Fernandez, C. G., Udayar, V., Vetrivel, K. S., Elie, A., Roseman, J., et al. (2013). A function for EHD family proteins in unidirectional retrograde dendritic transport of BACE1 and Alzheimer's disease Abeta production. Cell Rep. 5, 1552-1563. doi: 10.1016/j.celrep.2013.12.006 biological functions of BACE1 and BACE2 in brains and other tissues.

\section{AUTHOR CONTRIBUTIONS}

The author confirms being the sole contributor of this work and approved it for publication.

\section{FUNDING}

This study was supported by grants from the National Institutes of Health to RY (NS074256, AG025493, AG046929, and NM103942) and a grant from the National Multiple Sclerosis Society to RY (RG 4012A1/1).

Cai, J., Qi, X., Kociok, N., Skosyrski, S., Emilio, A., Ruan, Q., et al. (2012). betaSecretase (BACE1) inhibition causes retinal pathology by vascular dysregulation and accumulation of age pigment. EMBO Mol. Med. 4, 980-991. doi: 10.1002/ emmm.201101084

Cao, L., Rickenbacher, G. T., Rodriguez, S., Moulia, T. W., and Albers, M. W. (2012). The precision of axon targeting of mouse olfactory sensory neurons requires the BACE1 protease. Sci. Rep. 2:231. doi: 10.1038/srep00231

Casas, S., Casini, P., Piquer, S., Altirriba, J., Soty, M., Cadavez, L., et al. (2010). BACE2 plays a role in the insulin receptor trafficking in pancreatic beta-cells. Am. J. Physiol. Endocrinol. Metab. 299, E1087-E1095. doi: 10.1152/ajpendo. 00420.2010

Catterall, W. A. (2000). From ionic currents to molecular mechanisms: the structure and function of voltage-gated sodium channels. Neuron 26, 13-25. doi: 10.1016/S0896-6273(00)81133-2

Chang, H., Riese, D. J., Gilbert, W., Stern, D. F., and McMahan, U. J. (1997). Ligands for ErbB-family receptors encoded by a neuregulin-like gene. Nature 387, 509-512. doi: 10.1038/387509a0

Cheret, C., Willem, M., Fricker, F. R., Wende, H., Wulf-Goldenberg, A., Tahirovic, S., et al. (2013). Bacel and Neuregulin-1 cooperate to control formation and maintenance of muscle spindles. EMBO J. 32, 2015-2028. doi: 10.1038/emboj.2013.146

Chevallier, N., Vizzavona, J., Marambaud, P., Baur, C. P., Spillantini, M., Fulcrand, P., et al. (1997). Cathepsin D displays in vitro beta-secretase-like specificity. Brain Res. 750, 11-19. doi: 10.1016/S0006-8993(96)01330-3

Costantini, C., Ko, M. H., Jonas, M. C., and Puglielli, L. (2007). A reversible form of lysine acetylation in the ER and Golgi lumen controls the molecular stabilization of BACE1. Biochem. J. 407, 383-395. doi: 10.1042/BJ20070040

De Strooper, B., Saftig, P., Craessaerts, K., Vanderstichele, H., Guhde, G., Annaert, W., et al. (1998). Deficiency of presenilin-1 inhibits the normal cleavage of amyloid precursor protein. Nature 391, 387-390. doi: 10.1038/ 34910

Deng, M., He, W., Tan, Y., Han, H., Hu, X., Xia, K., et al. (2013). Increased expression of reticulon 3 in neurons leads to reduced axonal transport of beta site amyloid precursor protein-cleaving enzyme 1. J. Biol. Chem. 288, 30236-30245. doi: 10.1074/jbc.M113.480079

Dentchev, T., Milam, A. H., Lee, V. M., Trojanowski, J. Q., and Dunaief, J. L. (2003). Amyloid-beta is found in drusen from some age-related macular degeneration retinas, but not in drusen from normal retinas. Mol. Vis. 9, 184-190.

Dislich, B., Wohlrab, F., Bachhuber, T., Mueller, S., Kuhn, P. H., Hogl, S., et al. (2015). Label-free quantitative proteomics of mouse cerebrospinal fluid detects BACE1 protease substrates in vivo. Mol. Cell. Proteomics 14, 2550-2563. doi: 10.1074/mcp.M114.041533

Dominguez, D., Tournoy, J., Hartmann, D., Huth, T., Cryns, K., Deforce, S., et al. (2005). Phenotypical and biochemical analysis of BACE1 and BACE2 deficient mice. J. Biol. Chem. 280, 30797-30806. doi: 10.1074/jbc.M505249200

Esterhazy, D., Akpinar, P., and Stoffel, M. (2012). Tmem27 dimerization, deglycosylation, plasma membrane depletion, and the extracellular Phe-Phe 
motif are negative regulators of cleavage by Bace2. Biol. Chem. 393, 473-484. doi: $10.1515 / \mathrm{hsz}-2012-0104$

Esterhazy, D., Stutzer, I., Wang, H., Rechsteiner, M. P., Beauchamp, J., Dobeli, H., et al. (2011). Bace2 is a beta cell-enriched protease that regulates pancreatic beta cell function and mass. Cell Metab. 14, 365-377. doi: 10.1016/j.cmet.2011.06.018

Farzan, M., Schnitzler, C. E., Vasilieva, N., Leung, D., and Choe, H. (2000). BACE2, a $\beta$-secretase homolog, cleaves at the $\beta$ site and within the amyloid- $\beta$ region of the amyloid- $\beta$ precursor protein. Proc. Natl. Acad. Sci. U.S.A. 97, 9712-9717. doi: 10.1073/pnas.160115697

Fielden, M. R., Werner, J., Jamison, J. A., Coppi, A., Hickman, D., Dunn, R. T., et al. (2015). Retinal toxicity induced by a novel beta-secretase inhibitor in the sprague-dawley rat. Toxicol. Pathol. 43, 581-592. doi: 10.1177/ 0192623314553804

Filser, S., Ovsepian, S. V., Masana, M., Blazquez-Llorca, L., Brandt, E. A., Volbracht, C., et al. (2015). Pharmacological inhibition of BACE1 impairs synaptic plasticity and cognitive functions. Biol. Psychiatry 77, 729-739. doi: 10.1016/j.biopsych.2014.10.013

Finan, G. M., Okada, H., and Kim, T. W. (2011). BACE1 retrograde trafficking is uniquely regulated by the cytoplasmic domain of sortilin. J. Biol. Chem. 286, 12602-12616. doi: 10.1074/jbc.M110.170217

Fleck, D., Garratt, A. N., Haass, C., and Willem, M. (2012). BACE1 dependent neuregulin processing: review. Curr. Alzheimer Res. 9, 178-183. doi: 10.2174/ 156720512799361637

Fleck, D., van Bebber, F., Colombo, A., Galante, C., Schwenk, B. M., Rabe, L., et al. (2013). Dual cleavage of neuregulin 1 type III by BACE1 and ADAM17 liberates its EGF-like domain and allows paracrine signaling. J. Neurosci. 33, 7856-7869. doi: 10.1523/JNEUROSCI.3372-12.2013

Francis, R., McGrath, G., Zhang, J., Ruddy, D. A., Sym, M., Apfeld, J., et al. (2002). aph-1 and pen-2 are required for Notch pathway signaling, gamma-secretase cleavage of betaAPP, and presenilin protein accumulation. Dev. Cell 3, 85-97. doi: 10.1016/S1534-5807(02)00189-2

Fricker, F. R., Antunes-Martins, A., Galino, J., Paramsothy, R., La, R. F., Perkins, J., et al. (2013). Axonal neuregulin 1 is a rate limiting but not essential factor for nerve remyelination. Brain 136, 2279-2297. doi: 10.1093/brain/awt148

Fricker, F. R., Lago, N., Balarajah, S., Tsantoulas, C., Tanna, S., Zhu, N., et al. (2011). Axonally derived neuregulin-1 is required for remyelination and regeneration after nerve injury in adulthood. J. Neurosci. 31, 3225-3233. doi: 10.1523/ JNEUROSCI.2568-10.2011

Geddes, A. E., Huang, X.-F., and Newell, K. A. (2011). Reciprocal signalling between NR2 subunits of the NMDA receptor and neuregulin1 and their role in schizophrenia. Prog. Neuropsychopharmacol. Biol. Psychiatry 35, 896-904. doi: 10.1016/j.pnpbp.2011.02.017

Gersbacher, M. T., Kim, D. Y., Bhattacharyya, R., and Kovacs, D. M. (2010). Identification of BACE1 cleavage sites in human voltage-gated sodium channel beta 2 subunit. Mol. Neurodegener. 5:61. doi: 10.1186/1750-1326-5-61

Ghosh, A. K., and Osswald, H. L. (2014). BACE1 (beta-secretase) inhibitors for the treatment of Alzheimer's disease. Chem. Soc. Rev. 43, 6765-6813. doi: 10.1039/ c3cs60460h

Goldman, A. M., Glasscock, E., Yoo, J., Chen, T. T., Klassen, T. L., and Noebels, J. L. (2009). Arrhythmia in heart and brain: KCNQ1 mutations link epilepsy and sudden unexplained death. Sci. Transl. Med. 1, 2ra6. doi: 10.1126/scitranslmed. 3000289

Gruninger-Leitch, F., Berndt, P., Langen, H., Nelboeck, P., and Dobeli, H. (2000). Identification of beta-secretase-like activity using a mass spectrometry-based assay system. Nat. Biotechnol. 18, 66-70. doi: 10.1038/71944

Gruninger-Leitch, F., Schlatter, D., Kung, E., Nelbock, P., and Dobeli, H. (2002). Substrate and inhibitor profile of BACE (beta-secretase) and comparison with other mammalian aspartic proteases. J. Biol. Chem. 277, 4687-4693. doi: 10. 1074/jbc.M109266200

Gunnersen, J. M., Kim, M. H., Fuller, S. J., De Silva, M., Britto, J. M., Hammond, V. E., et al. (2007). Sez-6 proteins affect dendritic arborization patterns and excitability of cortical pyramidal neurons. Neuron 56, 621-639. doi: 10.1016/ j.neuron.2007.09.018

Gupta, V., Gupta, V. B., Chitranshi, N., Gangoda, S., Vander, W. R., Abbasi, M., et al. (2016). One protein, multiple pathologies: multifaceted involvement of amyloid beta in neurodegenerative disorders of the brain and retina. Cell Mol. Life Sci. 73, 4279-4297. doi: 10.1007/s00018-016-2295-x
Haniu, M., Denis, P., Young, Y., Mendiaz, E. A., Fuller, J., Hui, J. O., et al. (2000). Characterization of Alzheimer's beta -secretase protein BACE. A pepsin family member with unusual properties. J. Biol. Chem. 275, 21099-21106. doi: 10.1074/ jbc.M002095200

Harrison, P. J., and Law, A. J. (2006). Neuregulin 1 and schizophrenia: genetics, gene expression, and neurobiology. Biol. Psychiatry 60, 132-140. doi: 10.1016/j. biopsych.2005.11.002

He, W., Hu, J., Xia, Y., and Yan, R. (2014). beta-site amyloid precursor protein cleaving enzyme 1(BACE1) regulates Notch signaling by controlling the cleavage of Jagged 1 (Jag1) and Jagged 2 (Jag2) proteins. J. Biol. Chem. 289, 20630-20637. doi: 10.1074/jbc.M114.579862

He, X., Chang, W. P., Koelsch, G., and Tang, J. (2002). Memapsin 2 (beta-secretase) cytosolic domain binds to the VHS domains of GGA1 and GGA2: implications on the endocytosis mechanism of memapsin 2. FEBS Lett. 524, 183-187. doi: 10.1016/S0014-5793(02)03052-1

He, X., Li, F., Chang, W. P., and Tang, J. (2005). GGA proteins mediate the recycling pathway of memapsin 2 (BACE). J. Biol. Chem. 280, 11696-11703. doi: 10.1074/jbc.M411296200

Hemming, M. L., Elias, J. E., Gygi, S. P., and Selkoe, D. J. (2009). Identification of beta-secretase (BACE1) substrates using quantitative proteomics. PLoS ONE 4:e8477. doi: 10.1371/journal.pone.0008477

Heron, S. E., Hernandez, M., Edwards, C., Edkins, E., Jansen, F. E., Scheffer, I. E., et al. (2010). Neonatal seizures and long QT syndrome: a cardiocerebral channelopathy? Epilepsia 51, 293-296. doi: 10.1111/j.1528-1167.2009.02317.x

Hessler, S., Zheng, F., Hartmann, S., Rittger, A., Lehnert, S., Volkel, M., et al. (2015). beta-Secretase BACE1 regulates hippocampal and reconstituted M-currents in a beta-subunit-like fashion. J. Neurosci. 35, 3298-3311. doi: 10.1523/ JNEUROSCI.3127-14.2015

Hippenmeyer, S., Shneider, N. A., Birchmeier, C., Burden, S. J., Jessell, T. M., and Arber, S. (2002). A role for neuregulin1 signaling in muscle spindle differentiation. Neuron 36, 1035-1049. doi: 10.1016/S0896-6273(02)01101-7

Hitt, B. D., Jaramillo, T. C., Chetkovich, D. M., and Vassar, R. (2010). BACE1/- mice exhibit seizure activity that does not correlate with sodium channel level or axonal localization. Mol. Neurodegener. 5:31. doi: 10.1186/17501326-5-31

Hitt, B., Riordan, S. M., Kukreja, L., Eimer, W. A., Rajapaksha, T. W., and Vassar, R. (2012). $\beta$-site amyloid precursor protein (APP)-cleaving enzyme 1 (BACE1)deficient mice exhibit a close homolog of L1 (CHL1) loss-of-function phenotype involving axon guidance defects. J. Biol. Chem. 287, 38408-38425. doi: 10.1074/ jbc.M112.415505

Holmes, W. E., Sliwkowski, M. X., Akita, R. W., Henzel, W. J., Lee, J., Park, J. W., et al. (1992). Identification of heregulin, a specific activator of p185erbB2. Science 256, 1205-1210. doi: 10.1126/science.256.5060.1205

Hong, L., Koelsch, G., Lin, X., Wu, S., Terzyan, S., Ghosh, A. K., et al. (2000). Structure of the protease domain of memapsin 2 (beta-secretase) complexed with inhibitor. Science 290, 150-153. doi: 10.1126/science.290.5489.150

Hu, X., Fan, Q., Hou, H., and Yan, R. (2015a). Neurological dysfunctions associated with altered BACE1-dependent Neuregulin-1 signaling. J. Neurochem. 136, 234-249. doi: 10.1111/jnc.13395

Hu, X., He, W., Diaconu, C., Tang, X., Kidd, G. J., Macklin, W. B., et al. (2008). Genetic deletion of BACE1 in mice affects remyelination of sciatic nerves. FASEB J. 22, 2970-2980. doi: 10.1096/fj.08-106666

Hu, X., He, W., Luo, X., Tsubota, K. E., and Yan, R. (2013). BACE1 regulates hippocampal astrogenesis via the Jagged1-Notch pathway. Cell Rep. 4, 40-49. doi: 10.1016/j.celrep.2013.06.005

Hu, X., Hicks, C. W., He, W., Wong, P., Macklin, W. B., Trapp, B. D., et al. (2006). Bacel modulates myelination in the central and peripheral nervous system. Nat. Neurosci. 9, 1520-1525. doi: 10.1038/nn1797

Hu, X., Hou, H., Bastian, C., He, W., Qiu, S., Ge, Y., et al. (2017). BACE1 regulates the proliferation and cellular functions of Schwann cells. Glia 65, 712-726. doi: $10.1002 /$ glia.23122

Hu, X., Hu, J., Dai, L., Trapp, B., and Yan, R. (2015b). Axonal and Schwann cell BACE1 is equally required for remyelination of peripheral nerves. J. Neurosci. 35, 3806-3814. doi: 10.1523/JNEUROSCI.5207-14.2015

Hu, X., Zhou, X., He, W., Yang, J., Xiong, W., Wong, P., et al. (2010). BACE1 deficiency causes altered neuronal activity and neurodegeneration. J. Neurosci. 30, 8819-8829. doi: 10.1523/JNEUROSCI.1334-10.2010 
Hunt, C. C. (1990). Mammalian muscle spindle: peripheral mechanisms. Physiol. Rev. 70, 643-663.

Hussain, I., Powell, D., Howlett, D. R., Tew, D. G., Meek, T. D., Chapman, C., et al. (1999). Identification of a novel aspartic protease (Asp 2) as beta-secretase. Mol. Cell. Neurosci. 14, 419-427. doi: 10.1006/mcne.1999.0811

Huth, T., Rittger, A., Saftig, P., and Alzheimer, C. (2011). beta-Site APP-cleaving enzyme 1 (BACE1) cleaves cerebellar $\mathrm{Na}+$ channel beta4-subunit and promotes Purkinje cell firing by slowing the decay of resurgent $\mathrm{Na}+$ current. Pflugers. Arch. 461, 355-371. doi: 10.1007/s00424-010-0913-2

Isom, L. L. (2002). Beta subunits: players in neuronal hyperexcitability? Novartis Found Symp. 241, 124-138.

John, B. A., Meister, M., Banning, A., and Tikkanen, R. (2014). Flotillins bind to the dileucine sorting motif of beta-site amyloid precursor protein-cleaving enzyme 1 and influence its endosomal sorting. FEBS J. 281, 2074-2087. doi: $10.1111 /$ febs. 12763

Kandalepas, P. C., Sadleir, K. R., Eimer, W. A., Zhao, J., Nicholson, D. A., and Vassar, R. (2013). The Alzheimer's beta-secretase BACE1 localizes to normal presynaptic terminals and to dystrophic presynaptic terminals surrounding amyloid plaques. Acta Neuropathol. 126, 329-352. doi: 10.1007/s00401-0131152-3

Kang, E. L., Biscaro, B., Piazza, F., and Tesco, G. (2012). BACE1 protein endocytosis and trafficking are differentially regulated by ubiquitination at lysine 501 and the Di-leucine motif in the carboxyl terminus. J. Biol. Chem. 287, 42867-42880. doi: 10.1074/jbc.M112.407072

Kang, J., Lemaire, H. G., Unterbeck, A., Salbaum, J. M., Masters, C. L., Grzeschik, K. H., et al. (1987). The precursor of Alzheimer's disease amyloid A4 protein resembles a cell-surface receptor. Nature 325, 733-736. doi: 10.1038/325733a0

Kato, T., Kasai, A., Mizuno, M., Fengyi, L., Shintani, N., Maeda, S., et al. (2010). Phenotypic characterization of transgenic mice overexpressing neuregulin-1. PLoS ONE 5:e14185. doi: 10.1371/journal.pone.0014185

Khan, A. R., and James, M. N. (1998). Molecular mechanisms for the conversion of zymogens to active proteolytic enzymes. Protein Sci. 7, 815-836. doi: 10.1002/ pro.5560070401

Kim, D. Y., Carey, B. W., Wang, H., Ingano, L. A., Binshtok, A. M., Wertz, M. H., et al. (2007). BACE1 regulates voltage-gated sodium channels and neuronal activity. Nat. Cell Biol. 9, 755-764. doi: 10.1038/ncb1602

Kim, D. Y., Gersbacher, M. T., Inquimbert, P., and Kovacs, D. M. (2011). Reduced sodium channel $\mathrm{Na}(\mathrm{v}) 1.1$ levels in BACE1-null mice. J. Biol. Chem. 286, 81068116. doi: $10.1074 /$ jbc.M110.134692

Kim, D. Y., Ingano, L. A., Carey, B. W., Pettingell, W. H., and Kovacs, D. M. (2005). Presenilin/gamma-secretase-mediated cleavage of the voltage-gated sodium channel beta2-subunit regulates cell adhesion and migration. J. Biol. Chem. 280, 23251-23261. doi: 10.1074/jbc.M412938200

Kitazume, S., Tachida, Y., Oka, R., Kotani, N., Ogawa, K., Suzuki, M., et al. (2003). Characterization of $\alpha 2,6$-sialyltransferase cleavage by Alzheimer's $\beta$-secretase (BACE1). J. Biol. Chem. 278, 14865-14871. doi: 10.1074/jbc.M206262200

Kizuka, Y., Kitazume, S., Fujinawa, R., Saito, T., Iwata, N., Saido, T. C., et al. (2015). An aberrant sugar modification of BACE1 blocks its lysosomal targeting in Alzheimer's disease. EMBO Mol. Med. 7, 175-189. doi: 10.15252/emmm. 201404438

Kobayashi, D., Zeller, M., Cole, T., Buttini, M., McConlogue, L., Sinha, S., et al. (2008). BACE1 gene deletion: impact on behavioral function in a model of Alzheimer's disease. Neurobiol. Aging 29, 861-873. doi: 10.1016/j. neurobiolaging.2007.01.002

Kuhn, P. H., Koroniak, K., Hogl, S., Colombo, A., Zeitschel, U., Willem, M., et al. (2012). Secretome protein enrichment identifies physiological BACE1 protease substrates in neurons. EMBO J. 31, 3157-3168. doi: 10.1038/emboj.2012.173

Kuhn, P. H., Marjaux, E., Imhof, A., De Strooper, B., Haass, C., and Lichtenthaler, S. F. (2007). Regulated intramembrane proteolysis of the interleukin-1 receptor II by $\alpha$-, $\beta$-, and $\gamma$-secretase. J. Biol. Chem. 282, 11982-11995. doi: 10.1074/jbc. M700356200

La, M. R., Cerri, F., Horiuchi, K., Bachi, A., Feltri, M. L., Wrabetz, L., et al. (2011). TACE (ADAM17) inhibits Schwann cell myelination. Nat. Neurosci. 14, 857-865. doi: 10.1038/nn.2849

Leu, M., Bellmunt, E., Schwander, M., Farinas, I., Brenner, H. R., and Muller, U. (2003). Erbb2 regulates neuromuscular synapse formation and is essential for muscle spindle development. Development 130, 2291-2301. doi: 10.1242/dev. 00447
Li, L., Luo, J., Chen, D., Tong, J. B., Zeng, L. P., Cao, Y. Q., et al. (2016). BACE1 in the retina: a sensitive biomarker for monitoring early pathological changes in Alzheimer's disease. Neural Regen. Res. 11, 447-453. doi: 10.4103/1673-5374. 179057

Li, Y. M., Xu, M., Lai, M. T., Huang, Q., Castro, J. L., DiMuzio-Mower, J., et al. (2000). Photoactivated gamma-secretase inhibitors directed to the active site covalently label presenilin 1 . Nature 405, 689-694. doi: 10.1038/35015085

Lichtenthaler, S. F., Dominguez, D. I., Westmeyer, G. G., Reiss, K., Haass, C., Saftig, P., et al. (2003). The cell adhesion protein P-selectin glycoprotein ligand-1 is a substrate for the aspartyl protease BACE1. J. Biol. Chem. 278, 48713-48719. doi: 10.1074/jbc.M303861200

Lin, X., Koelsch, G., Wu, S., Downs, D., Dashti, A., and Tang, J. (2000). Human aspartic protease memapsin 2 cleaves the beta-secretase site of beta-amyloid precursor protein. Proc. Natl. Acad. Sci. U.S.A. 97, 1456-1460. doi: 10.1073/ pnas.97.4.1456

Liu, X., Bates, R., Yin, D. M., Shen, C., Wang, F., Su, N., et al. (2011). Specific regulation of NRG1 isoform expression by neuronal activity. J. Neurosci. 31, 8491-8501. doi: 10.1523/JNEUROSCI.5317-10.2011

Luo, X., He, W., Hu, X., and Yan, R. (2013). Reversible overexpression of bace1-cleaved neuregulin-1 N-terminal fragment induces schizophrenia-like phenotypes in mice. Biol. Psychiatry 76, 120-127. doi: 10.1016/j.biopsych.2013. 09.026

Luo, X., Prior, M., He, W., Hu, X., Tang, X., Shen, W., et al. (2011). Cleavage of neuregulin-1 by BACE1 or ADAM10 protein produces differential effects on myelination. J. Biol. Chem. 286, 23967-23974. doi: 10.1074/jbc.M111.251538

Mackay, E. A., Ehrhard, A., Moniatte, M., Guenet, C., Tardif, C., Tarnus, C., et al. (1997). A possible role for cathepsins D., E., and B in the processing of betaamyloid precursor protein in Alzheimer's disease. Eur. J. Biochem. 244, 414-425. doi: 10.1111/j.1432-1033.1997.00414.x

Masuzzo, A., Dinet, V., Cavanagh, C., Mascarelli, F., and Krantic, S. (2016). Amyloidosis in retinal neurodegenerative diseases. Front. Neurol. 7:127. doi: $10.3389 /$ fneur.2016.00127

Mei, L., and Nave, K. A. (2014). Neuregulin-ERBB signaling in the nervous system and neuropsychiatric diseases. Neuron 83, 27-49. doi: 10.1016/j.neuron.2014. 06.007

Michailov, G. V., Sereda, M. W., Brinkmann, B. G., Fischer, T. M., Haug, B., Birchmeier, C., et al. (2004). Axonal neuregulin-1 regulates myelin sheath thickness. Science 304, 700-703. doi: 10.1126/science.1095862

Morrison, S. J., Perez, S. E., Qiao, Z., Verdi, J. M., Hicks, C., Weinmaster, G., et al. (2000). Transient Notch activation initiates an irreversible switch from neurogenesis to gliogenesis by neural crest stem cells. Cell 101, 499-510. doi: 10.1016/S0092-8674(00)80860-0

Mukherjee, A., Morales-Scheihing, D., Butler, P. C., and Soto, C. (2015). Type 2 diabetes as a protein misfolding disease. Trends Mol. Med. 21, 439-449. doi: 10.1016/j.molmed.2015.04.005

Mulley, J. C., Iona, X., Hodgson, B., Heron, S. E., Berkovic, S. F., Scheffer, I. E., et al. (2011). The role of seizure-related SEZ6 as a susceptibility gene in febrile seizures. Neurol. Res. Int. 2011:917565. doi: 10.1155/2011/ 917565

Oehlrich, D., Prokopcova, H., and Gijsen, H. J. (2014). The evolution of amidinebased brain penetrant BACE1 inhibitors. Bioorg. Med. Chem. Lett. 24, 20332045. doi: 10.1016/j.bmcl.2014.03.025

Pastorino, L., Ikin, A. F., Nairn, A. C., Pursnani, A., and Buxbaum, J. D. (2002). The carboxyl-terminus of BACE contains a sorting signal that regulates BACE trafficking but not the formation of total A(beta). Mol. Cell. Neurosci. 19, 175-185. doi: 10.1006/mcne.2001.1065

Pigoni, M., Wanngren, J., Kuhn, P. H., Munro, K. M., Gunnersen, J. M., Takeshima, H., et al. (2016). Seizure protein 6 and its homolog seizure 6-like protein are physiological substrates of BACE1 in neurons. Mol. Neurodegener. 11:67. doi: 10.1186/s13024-016-0134-z

Rajapaksha, T. W., Eimer, W. A., Bozza, T. C., and Vassar, R. (2011). The Alzheimer's $\beta$-secretase enzyme BACE1 is required for accurate axon guidance of olfactory sensory neurons and normal glomerulus formation in the olfactory bulb. Mol. Neurodegener. 6:88. doi: 10.1186/1750-1326-6-88

Rochin, L., Hurbain, I., Serneels, L., Fort, C., Watt, B., Leblanc, P., et al. (2013). BACE2 processes PMEL to form the melanosome amyloid matrix in pigment cells. Proc. Natl. Acad. Sci. U.S.A. 110, 10658-10663. doi: 10.1073/pnas. 1220748110 
Rulifson, I. C., Cao, P., Miao, L., Kopecky, D., Huang, L., White, R. D., et al. (2016). Identification of human islet amyloid polypeptide as a BACE2 substrate. PLoS ONE 11:e0147254. doi: 10.1371/journal.pone.0147254

Rumsey, J. W., Das, M., Kang, J. F., Wagner, R., Molnar, P., and Hickman, J. J. (2008). Tissue engineering intrafusal fibers: dose- and time-dependent differentiation of nuclear bag fibers in a defined in vitro system using neuregulin 1-beta-1. Biomaterials 29, 994-1004. doi: 10.1016/j.biomaterials.2007. 10.042

Sachse, C. C., Kim, Y. H., Agsten, M., Huth, T., Alzheimer, C., Kovacs, D. M., et al. (2013). BACE1 and presenilin/gamma-secretase regulate proteolytic processing of KCNE1 and 2, auxiliary subunits of voltage-gated potassium channels. FASEB J. 27, 2458-2467. doi: 10.1096/fj.12-214056

Sadleir, K. R., Kandalepas, P. C., Buggia-Prevot, V., Nicholson, D. A., Thinakaran, G., and Vassar, R. (2016). Presynaptic dystrophic neurites surrounding amyloid plaques are sites of microtubule disruption, BACE1 elevation, and increased Abeta generation in Alzheimer's disease. Acta Neuropathol. 132, 235-256. doi: 10.1007/s00401-016-1558-9

Sannerud, R., Declerck, I., Peric, A., Raemaekers, T., Menendez, G., Zhou, L., et al. (2011). ADP ribosylation factor 6 (ARF6) controls amyloid precursor protein (APP) processing by mediating the endosomal sorting of BACE1. Proc. Natl. Acad. Sci. U.S.A. 108, E559-E568. doi: 10.1073/pnas.1100745108

Santosa, C., Rasche, S., Barakat, A., Bellingham, S. A., Ho, M., Tan, J., et al. (2011). Decreased expression of GGA3 protein in Alzheimer's disease frontal cortex and increased co-distribution of BACE with the amyloid precursor protein. Neurobiol. Dis. 43, 176-183. doi: 10.1016/j.nbd.2011.03.009

Savonenko, A. V., Melnikova, T., Laird, F. M., Stewart, K. A., Price, D. L., and Wong, P. C. (2008). Alteration of BACE1-dependent NRG1/ErbB4 signaling and schizophrenia-like phenotypes in BACE1-null mice. Proc. Natl. Acad. Sci. U.S.A. 105, 5585-5590. doi: 10.1073/pnas.0710373105

Sharoar, M. G., and Yan, R. (2017). Effects of altered RTN3 expression on BACE1 activity and Alzheimer's neuritic plaques. Rev. Neurosci. 28, 145-154. doi: 10. 1515/revneuro-2016-0054

Shi, X. P., Chen, E., Yin, K. C., Na, S., Garsky, V. M., Lai, M. T., et al. (2001). The pro domain of beta-secretase does not confer strict zymogen-like properties but does assist proper folding of the protease domain. J. Biol. Chem. 276, 10366-10373. doi: 10.1074/jbc.M009200200

Shimizu, H., Tosaki, A., Kaneko, K., Hisano, T., Sakurai, T., and Nukina, N. (2008). Crystal structure of an active form of BACE1, an enzyme responsible for amyloid beta protein production. Mol. Cell. Biol. 28, 3663-3671. doi: 10. 1128/MCB.02185-07

Shimshek, D. R., Jacobson, L. H., Kolly, C., Zamurovic, N., Balavenkatraman, K. K., Morawiec, L., et al. (2016). Pharmacological BACE1 and BACE2 inhibition induces hair depigmentation by inhibiting PMEL17 processing in mice. Sci. Rep. 6:21917. doi: 10.1038/srep21917

Sinha, S., Anderson, J. P., Barbour, R., Basi, G. S., Caccavello, R., Davis, D., et al. (1999). Purification and cloning of amyloid precursor protein beta-secretase from human brain. Nature 402, 537-540. doi: 10.1038/990114

Song, W. J., Son, M. Y., Lee, H. W., Seo, H., Kim, J. H., and Chung, S. H. (2015). Enhancement of BACE1 activity by p25/Cdk5-mediated phosphorylation in Alzheimer's disease. PLOS ONE 10:e0136950. doi: 10.1371/journal.pone. 0136950

Stassart, R. M., Fledrich, R., Velanac, V., Brinkmann, B. G., Schwab, M. H., Meijer, D., et al. (2013). A role for Schwann cell-derived neuregulin-1 in remyelination. Nat. Neurosci. 16, 48-54. doi: 10.1038/nn.3281

Stefansson, H., Sigurdsson, E., Steinthorsdottir, V., Bjornsdottir, S., Sigmundsson, T., and Ghosh, S. (2002). Neuregulin 1 and susceptibility to schizophrenia. Am. J. Hum. Genet. 71, 877-892. doi: 10.1086/ 342734

Steuble, M., Diep, T. M., Schatzle, P., Ludwig, A., Tagaya, M., Kunz, B., et al. (2012). Calsyntenin-1 shelters APP from proteolytic processing during anterograde axonal transport. Biol. Open 1, 761-774. doi: 10.1242/bio.20121578

Stutzer, I., Selevsek, N., Esterhazy, D., Schmidt, A., Aebersold, R., and Stoffel, M. (2013). Systematic proteomic analysis identifies beta-site amyloid precursor protein cleaving enzyme 2 and 1 (BACE2 and BACE1) substrates in pancreatic beta-cells. J. Biol. Chem. 288, 10536-10547. doi: 10.1074/jbc.M112. 444703

Tanzi, R. E., Gusella, J. F., Watkins, P. C., Bruns, G. A., St George-Hyslop, P., Van Keuren, M. L., et al. (1987). Amyloid beta protein gene: cDNA, mRNA distribution, and genetic linkage near the Alzheimer locus. Science 235, 880884. doi: 10.1126/science.2949367

Taveggia, C., Thaker, P., Petrylak, A., Caporaso, G. L., Toews, A., Falls, D. L., et al. (2008). Type III neuregulin-1 promotes oligodendrocyte myelination. Glia 56, 284-293. doi: 10.1002/glia.20612

Taveggia, C., Zanazzi, G., Petrylak, A., Yano, H., Rosenbluth, J., Einheber, S., et al. (2005). Neuregulin-1 type III determines the ensheathment fate of axons. Neuron 47, 681-694. doi: 10.1016/j.neuron.2005.08.017

Tesco, G., Koh, Y. H., Kang, E. L., Cameron, A. N., Das, S., Sena-Esteves, M., et al. (2007). Depletion of GGA3 stabilizes BACE and enhances beta-secretase activity. Neuron 54, 721-737. doi: 10.1016/j.neuron.2007.05.012

Tomasselli, A. G., Qahwash, I., Emmons, T. L., Lu, Y., Leone, J. W., Lull, J. M., et al. (2003). Employing a superior BACE1 cleavage sequence to probe cellular APP processing. J. Neurochem. 84, 1006-1017. doi: 10.1046/j.1471-4159.2003. 01597.x

Treiber, H., Hagemeyer, N., Ehrenreich, H., and Simons, M. (2012). BACE1 in central nervous system myelination revisited. Mol. Psychiatry 17, 237-239. doi: $10.1038 / \mathrm{mp} .2011 .140$

Turner, R. T. III, Loy, J. A., Nguyen, C., Devasamudram, T., Ghosh, A. K., Koelsch, G., et al. (2002). Specificity of memapsin 1 and its implications on the design of memapsin 2 (beta-secretase) inhibitor selectivity. Biochemistry 41, 8742-8746. doi: 10.1021/bi025926t

Udayar, V., Buggia-Prevot, V., Guerreiro, R. L., Siegel, G., Rambabu, N., Soohoo, A. L., et al. (2013). A paired RNAi and RabGAP overexpression screen identifies Rab11 as a regulator of beta-amyloid production. Cell Rep. 5, 1536-1551. doi: 10.1016/j.celrep.2013.12.005

Vagnoni, A., Perkinton, M. S., Gray, E. H., Francis, P. T., Noble, W., and Miller C. C. (2012). Calsyntenin-1 mediates axonal transport of the amyloid precursor protein and regulates Abeta production. Hum. Mol. Genet. 21, 2845-2854. doi: $10.1093 / \mathrm{hmg} / \mathrm{dds} 109$

van Bebber, F., Hruscha, A., Willem, M., Schmid, B., and Haass, C. (2013). Loss of Bace2 in zebrafish affects melanocyte migration and is distinct from Bace1 knock out phenotypes. J. Neurochem. 127, 471-481. doi: 10.1111/jnc. 12198

Vassar, R. (2014). BACE1 inhibitor drugs in clinical trials for Alzheimer's disease. Alzheimers Res. Ther. 6:89. doi: 10.1186/s13195-014-0089-7

Vassar, R., Bennett, B. D., Babu-Khan, S., Kahn, S., Mendiaz, E. A., Denis, P., et al. (1999). Beta-secretase cleavage of Alzheimer's amyloid precursor protein by the transmembrane aspartic protease BACE. Science 286, 735-741. doi: 10.1126/ science.286.5440.735

Vassar, R., Kovacs, D. M., Yan, R., and Wong, P. C. (2009). The $\beta$-secretase enzyme BACE in health and Alzheimer's disease: regulation, cell biology, function, and therapeutic potential. J. Neurosci. 29, 12787-12794. doi: 10.1523/JNEUROSCI. 3657-09.2009

Vassar, R., Kuhn, P.-H., Haass, C., Kennedy, M. E., Rajendran, L., Wong, P. C., et al. (2014). Function, therapeutic potential and cell biology of BACE proteases: current status and future prospects. J. Neurochem. 130, 4-28. doi: 10.1111/jnc. 12715

Vetrivel, K. S., Meckler, X., Chen, Y., Nguyen, P. D., Seidah, N. G., Vassar, R., et al. (2009). Alzheimer disease Abeta production in the absence of S-palmitoylationdependent targeting of BACE1 to lipid rafts. J. Biol. Chem. 284, 3793-3803. doi: 10.1074/jbc.M808920200

von, E. B., Wahler, A., Schips, T., Serrano-Pozo, A., Proepper, C., Boeckers, T. M., et al. (2015). The golgi-localized gamma-ear-containing ARF-binding (GGA) proteins alter amyloid-beta precursor protein (APP) processing through interaction of their GAE domain with the beta-site APP cleaving enzyme 1 (BACE1). PLoS ONE 10:e0129047. doi: 10.1371/journal.pone. 0129047

Wahle, T., Prager, K., Raffler, N., Haass, C., Famulok, M., and Walter, J. (2005). GGA proteins regulate retrograde transport of BACE1 from endosomes to the trans-Golgi network. Mol. Cell. Neurosci. 29, 453-461. doi: 10.1016/j.mcn.2005. 03.014

Walker, K. R., Kang, E. L., Whalen, M. J., Shen, Y., and Tesco, G. (2012). Depletion of GGA1 and GGA3 mediates postinjury elevation of BACE1. J. Neurosci. 32, 10423-10437. doi: 10.1523/JNEUROSCI.5491-11.2012

Walter, J., Fluhrer, R., Hartung, B., Willem, M., Kaether, C., Capell, A., et al. (2001). Phosphorylation regulates intracellular trafficking of beta-secretase. J. Biol. Chem. 276, 14634-14641. doi: 10.1074/jbc.M011116200 
Wang, C. L., Tang, F. L., Peng, Y., Shen, C. Y., Mei, L., and Xiong, W. C. (2012). VPS35 regulates developing mouse hippocampal neuronal morphogenesis by promoting retrograde trafficking of BACE1. Biol. Open 1, 1248-1257. doi: 10. 1242/bio.20122451

Wang, H., Megill, A., Wong, P. C., Kirkwood, A., and Lee, H. K. (2014). Postsynaptic target specific synaptic dysfunctions in the CA3 area of BACE1 knockout mice. PLOS ONE 9:e92279. doi: 10.1371/journal.pone. 0092279

Wang, H., Song, L., Laird, F., Wong, P. C., and Lee, H. K. (2008). BACE1 knockouts display deficits in activity-dependent potentiation of synaptic transmission at mossy fiber to CA3 synapses in the hippocampus. J. Neurosci. 28, 8677-8681. doi: 10.1523/JNEUROSCI.2440-08.2008

Wang, R., Ying, Z., Zhao, J., Zhang, Y., Wang, R., Lu, H., et al. (2012). Lys(203) and Lys(382) are essential for the proteasomal degradation of BACE1. Curr. Alzheimer Res. 9, 606-615. doi: 10.2174/156720512800 618026

Warren, C. M., Kani, K., and Landgraf, R. (2006). The N-terminal domains of neuregulin 1 confer signal attenuation. J. Biol. Chem. 281, 27306-27316. doi: 10.1074/jbc.M512887200

Weber, M., Wu, T., Meilandt, W. J., Dominguez, S. L., Solanoy, H. O., Maloney, J. A., et al. (2017). BACE1 across species: a comparison of the in vivo consequences of BACE1 deletion in mice and rats. Sci. Rep. 7:44249. doi: 10. 1038/srep44249

Wen, L., Tang, F. L., Hong, Y., Luo, S. W., Wang, C. L., He, W., et al. (2011). VPS35 haploinsufficiency increases Alzheimer's disease neuropathology. J. Cell Biol. 195, 765-779. doi: 10.1083/jcb.201105109

Willem, M., Garratt, A. N., Novak, B., Citron, M., Kaufmann, S., Rittger, A., et al. (2006). Control of peripheral nerve myelination by the beta-secretase BACE1. Science 314, 664-666. doi: 10.1126/science.1132341

Wolfe, M. S., De Los, A. J., Miller, D. D., Xia, W., and Selkoe, D. J. (1999). Are presenilins intramembrane-cleaving proteases? Implications for the molecular mechanism of Alzheimer's disease. Biochemistry 38, 11223-11230. doi: 10.1021/ bi991080q

Wong, H. K., Sakurai, T., Oyama, F., Kaneko, K., Wada, K., Miyazaki, H., et al. (2005). beta Subunits of voltage-gated sodium channels are novel substrates of beta-site amyloid precursor protein-cleaving enzyme (BACE1) and gamma-secretase. J. Biol. Chem. 280, 23009-23017. doi: 10.1074/jbc.M414 648200

Xiong, K., Cai, H., Luo, X. G., Struble, R. G., Clough, R. W., and Yan, X. X. (2007). Mitochondrial respiratory inhibition and oxidative stress elevate beta-secretase (BACE1) proteins and activity in vivo in the rat retina. Exp. Brain Res. 181, 435-446. doi: 10.1007/s00221-007-0943-y

Yan, R. (2016). Stepping closer to treating Alzheimer's disease patients with BACE1 inhibitor drugs. Transl. Neurodegener. 5:13. doi: 10.1186/s40035-0160061-5

Yan, R., Bienkowski, M. J., Shuck, M. E., Miao, H., Tory, M. C., Pauley, A. M., et al. (1999). Membrane-anchored aspartyl protease with Alzheimer's disease beta-secretase activity. Nature 402, 533-537. doi: 10.1038/990107
Yan, R., Fan, Q., Zhou, J., and Vassar, R. (2016). Inhibiting BACE1 to reverse synaptic dysfunctions in Alzheimer's disease. Neurosci. Biobehav. Rev. 65, 326340. doi: 10.1016/j.neubiorev.2016.03.025

Yan, R., Han, P., Miao, H., Greengard, P., and Xu, H. (2001a). The transmembrane domain of the Alzheimer's beta-secretase (BACE1) determines its late Golgi localization and access to beta -amyloid precursor protein (APP) substrate. J. Biol. Chem. 276, 36788-36796. doi: 10.1074/jbc.M104350200

Yan, R., Munzner, J. B., Shuck, M. E., and Bienkowski, M. J. (2001b). BACE2 functions as an alternative $\alpha$-secretase in cells. J. Biol. Chem. 276, 34019-34027. doi: 10.1074/jbc.M105583200

Yan, R., and Vassar, R. (2014). Targeting the beta secretase BACE1 for Alzheimer's disease therapy. Lancet Neurol. 13, 319-329. doi: 10.1016/S1474-4422(13) 70276-X

Yeates, E. F., and Tesco, G. (2016). The endosome-associated deubiquitinating enzyme USP8 regulates BACE1 enzyme ubiquitination and degradation. J. Biol. Chem. 291, 15753-15766. doi: 10.1074/jbc.M116.718023

Yin, D. M., Chen, Y. J., Lu, Y. S., Bean, J. C., Sathyamurthy, A., Shen, C., et al. (2013). Reversal of behavioral deficits and synaptic dysfunction in mice overexpressing neuregulin 1. Neuron 78, 644-657. doi: 10.1016/j.neuron.2013. 03.028

Yu, E. J., Ko, S. H., Lenkowski, P. W., Pance, A., Patel, M. K., and Jackson, A. P. (2005). Distinct domains of the sodium channel beta3-subunit modulate channel-gating kinetics and subcellular location. Biochem. J. 392, 519-526. doi: 10.1042/BJ20050518

Yu, G., Nishimura, M., Arawaka, S., Levitan, D., Zhang, L., Tandon, A., et al. (2000). Nicastrin modulates presenilin-mediated notch/glp-1 signal transduction and betaAPP processing. Nature 407, 48-54. doi: 10.1038/35024009

Zhao, Y., Wang, Y., Yang, J., Wang, X., Zhao, Y., Zhang, X., et al. (2012). Sorting nexin 12 interacts with BACE1 and regulates BACE1-mediated APP processing. Mol. Neurodegener. 7:30. doi: 10.1186/1750-1326-7-30

Zhou, L., Barao, S., Laga, M., Bockstael, K., Borgers, M., Gijsen, H., et al. (2012). The neural cell adhesion molecules $\mathrm{L} 1$ and CHL1 are cleaved by BACE1 protease in vivo. J. Biol. Chem. 287, 25927-25940. doi: 10.1074/jbc.M112.377465

Zuhl, A. M., Nolan, C. E., Brodney, M. A., Niessen, S., Atchison, K., Houle, C., et al. (2016). Chemoproteomic profiling reveals that cathepsin D off-target activity drives ocular toxicity of beta-secretase inhibitors. Nat. Commun. 7:13042. doi: $10.1038 /$ ncomms 13042

Conflict of Interest Statement: The author declares that the research was conducted in the absence of any commercial or financial relationships that could be construed as a potential conflict of interest.

Copyright (c) 2017 Yan. This is an open-access article distributed under the terms of the Creative Commons Attribution License (CC BY). The use, distribution or reproduction in other forums is permitted, provided the original author (s) or licensor are credited and that the original publication in this journal is cited, in accordance with accepted academic practice. No use, distribution or reproduction is permitted which does not comply with these terms. 